\title{
Serum Zinc Levels and Immune Status of Children with Persistent Diarrhea Following Oral Zinc Supplementation
}

\author{
Yufen Jiang, Kedar Mandal, Hongzhu Lu* \\ Department of Pediatrics, The First Clinical College, Yangtze University, Jingzhou, China \\ Email: *lucas215@163.com
}

How to cite this paper: Jiang, Y.F., Mandal, K. and Lu, H.Z. (2021) Serum Zinc Levels and Immune Status of Children with Persistent Diarrhea Following Oral Zinc Supplementation. Yangtze Medicine, 5, 33-42. https://doi.org/10.4236/ym.2021.51004

Received: October 7, 2019

Accepted: January 10, 2021

Published: January 13, 2021

Copyright $\odot 2021$ by author(s) and Scientific Research Publishing Inc. This work is licensed under the Creative Commons Attribution International License (CC BY 4.0).

http://creativecommons.org/licenses/by/4.0/

\begin{abstract}
Background: Persistent diarrhea (PD) is a common disease in childhood worldwide. Clinical studies suggested that zinc supplementation is useful in most PD children. However, the relationship between the zinc and immune status of the PD children has not been reported. Objective: To examine serum zinc levels and immune status in 6 to 24 months old children with PD before and after 120 days of oral zinc supplementation and to evaluate the effects of zinc supplementation on serum zinc levels and immune status in PD children. Methods: A case control study was carried. Fifty-eight children aged 6 to 24 months with PD were enrolled. 58 patients were divided into two groups, zinc group (28 cases) and control group (30 cases). Laboratory investigation of serum zinc levels, Lymphocyte subsets (CD3+\%, CD4+\%, CD8+\% and $\mathrm{CD} 4+/ \mathrm{CD} 8+$ ratio) and immunoglobulins (IgG, $\operatorname{IgA}$ and $\operatorname{IgM}$ ) levels was carried out in all these patients once at enrollment and again after 120 days of treatment. Results: Before treatment, the serum zinc concentration was 4.37 $\pm 1.23 \mu \mathrm{mol} / \mathrm{L}$ in zinc group and $4.42 \pm 1.45 \mu \mathrm{mol} / \mathrm{L}$ in control group $(P>$ $0.05)$. However, after treatment, the serum zinc concentrations in the zinc group were significantly higher $(8.81 \pm 2.56 \mu \mathrm{mol} / \mathrm{L})$, as compared to the control group $(4.12 \pm 1.02 \mu \mathrm{mol} / \mathrm{L})(P<0.05)$. Regarding immune status, Lymphocyte subsets $\mathrm{CD} 3+\%, \mathrm{CD} 4+\%, \mathrm{CD} 8+\%$ and $\mathrm{CD} 4+/ \mathrm{CD} 8+$ ratio and IgG, IgA and IgM levels of all the children with PD were measured once at enrollment and again after 120 days of treatment. There were no significant differences between the zinc and the control groups in $\mathrm{CD} 3+\%, \mathrm{CD} 4+\%$, $\mathrm{CD} 8+\%$ and $\mathrm{CD} 4+/ \mathrm{CD} 8+$ ratios $(P>0.05)$ before giving treatment. However, after 120 days of treatment, in the zinc group there was a significant rise in $\mathrm{CD} 4+\%(53.60 \pm 5.78)$. The CD4 was significantly higher in the zinc group as compared to the control group $(44.73 \pm 4.39)(P<0.05)$. Besides CD $4+\%$, the
\end{abstract}


CD4+/CD8+ ratio was also found to be higher among zinc group $(1.49 \pm$ $0.29)$ as compared to the control group $(1.26 \pm 0.18)$ after treatment $(P<$ $0.05)$. But there were no statistically significant differences in CD $3+\%$ and $\mathrm{CD} 8+\%$ between zinc and control group after treatment $(P>0.05)$. Regarding immunoglobulins, there were no significant differences between zinc and control group in IgG, IgA and IgM levels $(P>0.05)$ at the time of enrollment (before treatment). However, after treatment, the mean IgG levels in zinc group and control group were $6.36 \pm 0.95 \mathrm{~g} / \mathrm{l}$ and $5.67 \pm 0.74 \mathrm{~g} / \mathrm{l}$, respectively, $P<0.05$. Similarly, after treatment, IgM levels in the zinc group were found significantly higher $(1.58 \pm 0.13 \mathrm{~g} / \mathrm{l})$, as compared to the control group (1.43 $\pm 0.20 \mathrm{~g} / \mathrm{l})(P<0.05)$ but no significant differences in IgA levels were evident between the two groups after treatment. Conclusion: Administration of oral zinc supplement improved both serum zinc levels and immune status in children with PD. Zinc supplementation should be administered as adjunctive therapy for PD children.

\section{Keywords}

Persistent Diarrhea, Children, Zinc, Immune Status

\section{Introduction}

Diarrhea is a major health problem in pediatrics worldwide. It is the second leading cause of death of children in developing countries and contributes to 1.5 - 2.5 million deaths annually in children under the age of five [1]. According to World Health Organization (WHO), diarrhea is defined as the passage of loose or watery stool at least three times within 24 hours. Persistent diarrhea (PD) occurs for a minimum of 14 days with or without blood in the stools. PD is associated with over $50 \%$ of diarrhea-related deaths in developing countries [1]. Most deaths occur in young children living in the rural areas, where adequate sanitation is unavailable [2]. Recurring episodes of diarrhea disease in the first years of life usually lead to malabsorption and subsequent malnutrition. Many studies have shown that diarrhea contributes to malnutrition. However, several recent studies have shown that malnutrition is also a risk factor for prolonged diarrhea; thus, in malnourished children, the mean duration of diarrhea episodes is longer and there is a higher incidence of PD [3].

As the onset of PD is most often at a critical stage of physical and mental development, it can have a serious adverse impact on growth curves, intellectual and cognitive function, and future educational performance, and can also increase morbidity and mortality due to other diseases [4]. PD continues to pose a challenge to pediatricians in terms of its pathophysiology and clinical management [5]. Zinc supplementation is useful in most PD children. However, the relationship between the zinc and immune status of the PD children is unclear, so we investigate serum zinc and immune status of children with PD. 


\section{Materials and Methods}

\subsection{Study Population}

Patients attending the pediatric outpatient department or admitted in the inpatient wards of First Affiliated Hospital of Yangtze University, fulfilling the inclusion criteria were evaluated clinically with detailed history, physical examination and laboratory investigations. The study was conducted from December 2017 to December 2018.

The study protocol was approved by the Ethics Committee of the People's First Hospital of Jingzhou Affiliated to Yangtze University.

Inclusion criteria: Patients aged 6 to 24 months with a diagnosis of persistent diarrhea (Lasting 14 days or more) were selected.

Exclusion criteria: Children known to have Pneumonia, severe malnutrition, Measles, Malaria, TB, HIV, AIDS, Meningitis, UTI, Hepatitis, Hyperthyroidism, Hypothyroidism, Epilepsy, and other diseases. Genetic and metabolic disorders. The children taking zinc compounds. Known allergy or intolerance to zinc or zinc containing products. Refused consent.

Fifty-eight patients with PD were enrolled and divided into two groups. Zinc group and control group, in zinc group, patients were treated with antibiotics, ORS and zinc supplementation. Control groups were treated with antibiotics and ORS without zinc supplementation.

After detailed physical examination, laboratory investigation of serum zinc levels, lymphocyte subsets CD3, CD4, CD8 and immunoglobulins-IgG, IgA, IgM levels were carried out in all the patients with PD before and after 120 days of treatment.

\subsection{Detection of Serum Zinc Levels}

For the zinc analysis, $3 \mathrm{ml}$ of venous blood from each patient was collected aseptically into plastic tubes (Nalgene Sybron Corporation, Rockester, New York) and centrifuged within one hour to avoid haemolysis. The serum obtained was frozen at $-20^{\circ} \mathrm{C}$ until the zinc analysis. Serum zinc levels were measured with atomic absorption spectrometry (AAS) [6]. Data were expressed as micromoles/litre.

\subsection{Detection of Lymphocyte Subsets}

CD3, CD4, CD8 and Immunoglobulins-IgG, IgA, IgM levels: $2 \mathrm{ml}$ of fresh venous blood was collected aseptically in heparin-coated sterile vials (Vacutainer system; Becton Dickinson, Rutherford, NY). Whole blood samples were analyzed with a Multi-Q-Prep processor (Beckman Coulter, FL, USA) and then the Epics-XL (Beckman Coulter) flow cytometer. Lymphocytes were analyzed using a gate set on forward scatter versus side scatter, and a three-color flow cytometry combination reagent of $\mathrm{CD} 3, \mathrm{CD} 4$ and $\mathrm{CD} 8$. Anti-human monoclonal antibodies CD3-PE-CY5/CD4-FITC/CD8-PE were from Immunotech, Ltd, MO, USA. For each sample, the detection was analysed with the CELLQuest 
software (Beckman Coulter). The results were expressed as the percentages of $\mathrm{CD} 3+, \mathrm{CD} 4+$ and $\mathrm{CD} 8+$ cells.

The concentrations of total IgG, IgA and IgM in serum were determined by immunoturbidimetric assay [7]. Results were expressed as gram per liters (g/l) of serum.

\subsection{Intervention}

Oral zinc supplementation was only administered to 28 persistent diarrhea cases along with other treatment (treatment with ORS, and antibiotics) whereas the control groups were only treated with ORS and antibiotics but not given zinc supplementation. The zinc preparation contained zinc gluconate $(0.5 \mathrm{mg} / 10 \mathrm{ml})$ in syrup form manufactured by Harbin Pharmaceutical Group in Harbin, China. A fixed dose of zinc syrup $10 \mathrm{ml}$ bid daily was administered to the children aged $<1$ year and $10 \mathrm{ml}$ tid daily to the children aged $>1$ year for 120 days since the time of enrollment. A repeat full dose was given if the child vomited within an hour of taking the treatment.

\subsection{Statistical Analysis}

SPSS.20.0 software was used in this study for statistical analysis and data processing. The comparison between the groups was done using independent $\mathrm{t}$-test. All the measurement data were expressed as mean \pm standard deviation. $P$-values $<0.05$ were considered statistically significant.

\section{Results}

\subsection{Demographic Characteristics of Children with Persistent Diarrhea}

A total of 58 children diagnosed with persistent diarrhea were enrolled in the study, of which 28 patients were allocated to zinc group and 30 patients to control group. Children with PD treated with antibiotics, ORS and zinc supplementation were selected as zinc group, whereas children with PD treated with antibiotics and ORS without zinc supplementation were selected as control group. Out of 58 subjects, total males among zinc and control group were 12 (42.86\%) and 16 (53.33\%), respectively, whereas, total females among zinc and control group were 16 (57.14\%) and 14 (46.67\%), respectively.

The children selected for the study were between 6 to 24 months of age with the mean age of $14.82 \pm 5.86$ months in zinc group and $14.23 \pm 5.48$ months in control group. There was no statistically significant difference in age between the two groups $(P>0.05)$.

\subsection{Zinc Status of Children with Persistent Diarrhea}

In a sample of 58 selected children with PD (zinc group 28, control group 30), serum zinc levels were measured once at enrollment and again after 120 days of treatment. The serum zinc levels at baseline (before treatment) and after treat- 
ment were then compared between the zinc and control groups.

At baseline, the mean serum zinc concentration was $4.37 \pm 1.23 \mu \mathrm{mol} / \mathrm{L}$ in zinc group and $4.42 \pm 1.45 \mu \mathrm{mol} / \mathrm{L}$ in control group $(P>0.05)$.

However, after treatment the serum zinc concentrations in the zinc group was significantly higher $(8.81 \pm 2.56 \mu \mathrm{mol} / \mathrm{L})$, as compared to the control group (4.12 $\pm 1.02 \mu \mathrm{mol} / \mathrm{L})(P<0.05)$ as shown in Table 1 .

\subsection{Immune Status of Children with Persistent Diarrhea}

\section{Lymphocyte Subset Results}

In a sample of 58 selected children with PD (zinc 28, control 30), lymphocyte subsets $(\mathrm{CD} 3+\%, \mathrm{CD} 4+\%, \mathrm{CD} 8+\%$ and $\mathrm{CD} 4+/ \mathrm{CD} 8+$ ratio) were measured once at enrollment and again after 120 days of treatment.

Before treatment, there were no significant differences between the zinc and the control groups in $\mathrm{CD} 3+\%, \mathrm{CD} 4+\%, \mathrm{CD} 8+\%$ and $\mathrm{CD} 4+/ \mathrm{CD} 8+$ ratios $(P>$ $0.05)$. However, after treatment, in the zinc group there was a significant rise in $\mathrm{CD} 4+\%(53.60 \pm 5.78)$. The CD4 rise was significantly higher in the zinc group as compared to the control group $(44.73 \pm 4.39)$ which was statistically evident $(P<0.05)$. Besides CD4+\%, the CD4+/CD8+ ratio was also found to be higher among zinc group $(1.49 \pm 0.29)$ as compared to the control group (1.26 \pm 0.18$)$ after treatment, as showed in Table 2.

\section{Immunoglobulin Results}

The immunoglobulin levels, IgG, IgA and IgM of all the 58 selected children with PD (zinc 28, control 30) were measured once at enrollment and again after 120 days of treatment. The data were showed in Table 3.

Table 1. Effect of zinc supplementation on serum zinc levels in children with PD.

\begin{tabular}{cccc}
\hline & Zinc group $(\mathrm{n}=28)$ & Control group $(\mathrm{n}=30)$ & \multirow{2}{*}{$P$ value } \\
\cline { 2 - 3 } Serum zinc $(\mu \mathrm{mol} / \mathrm{L})$ & Mean $\pm \mathrm{SD}$ & Mean $\pm \mathrm{SD}$ & \\
\hline Before treatment & $4.37 \pm 1.23$ & $4.42 \pm 1.45$ & 0.246 \\
After treatment & $8.81 \pm 2.56$ & $4.12 \pm 1.02$ & 0.001 \\
\hline
\end{tabular}

Table 2. Effect of zinc supplementation on Lymphocyte subsets CD3+\%, CD4+\%, CD8+\% and $\mathrm{CD} 4+/ \mathrm{CD} 8+$ ratio in children with $\mathrm{PD}$.

\begin{tabular}{ccccc}
\hline \multirow{2}{*}{ Cell subsets } & Sample & Zinc group $(\mathrm{n}=28)$ & Control group $(\mathrm{n}=30)$ & \multirow{2}{*}{ collection } \\
\cline { 3 - 4 } & Before & Mean $\pm \mathrm{SD}$ & Mean $\pm \mathrm{SD}$ & \\
\hline \multirow{2}{*}{$\mathrm{CD} 3+\%$} & $64.88 \pm 6.66$ & $64.22 \pm 5.49$ & 0.485 \\
& After & $62.99 \pm 10.93$ & $65.44 \pm 5.52$ & 0.436 \\
$\mathrm{CD} 4+\%$ & Before & $44.25 \pm 4.66$ & $44.40 \pm 4.54$ & 0.578 \\
& After & $53.60 \pm 5.78$ & $44.73 \pm 4.39$ & 0.001 \\
$\mathrm{CD} 8+\%$ & Before & $37.75 \pm 5.09$ & $38.07 \pm 5.00$ & 0.612 \\
& After & $36.42 \pm 5.07$ & $36.51 \pm 4.08$ & 0.523 \\
$\mathrm{CD} 4+/ \mathrm{CD} 8+$ & Before & $1.18 \pm 0.13$ & $1.18 \pm 0.12$ & 0.613 \\
& After & $1.49 \pm 0.29$ & $1.26 \pm 0.18$ & 0.002 \\
\hline
\end{tabular}


Table 3. Effect of zinc supplementation on Immunoglobulin levels-IgG, IgA and IgM in children with PD.

\begin{tabular}{|c|c|c|c|c|}
\hline \multirow{2}{*}{ Immuno-globulins $(\mathrm{g} / \mathrm{l})$} & \multirow{2}{*}{$\begin{array}{c}\text { Sample } \\
\text { collection }\end{array}$} & Zinc group $(n=28)$ & Control group $(\mathrm{n}=30)$ & \multirow{2}{*}{$P$ value } \\
\hline & & Mean \pm SD & Mean \pm SD & \\
\hline \multirow{2}{*}{ IgG } & Before & $5.49 \pm 0.72$ & $5.48 \pm 0.73$ & 0.428 \\
\hline & After & $6.36 \pm 0.95$ & $5.67 \pm 0.74$ & 0.003 \\
\hline \multirow{2}{*}{ IgA } & Before & $0.43 \pm 0.06$ & $0.41 \pm 0.06$ & 0.341 \\
\hline & After & $0.76 \pm 0.09$ & $0.75 \pm 0.09$ & 0.411 \\
\hline \multirow{2}{*}{ IgM } & Before & $1.18 \pm 0.19$ & $1.23 \pm 0.17$ & 0.231 \\
\hline & After & $1.58 \pm 0.13$ & $1.43 \pm 0.20$ & 0.012 \\
\hline
\end{tabular}

\section{Discussion}

In developing countries, diarrhoea causes around 500,000 child deaths annually. Zinc supplementation during acute diarrhoea is currently recommended by the World Health Organization (WHO) and the United Nations Children's Fund (UNICEF). There are fewer data about zinc supplementation in PD children. We firstly investigate the relationship between the zinc supplementation and immune status in PD children and suggest that zinc supplementation improves the immune status and is beneficial in for the PD children.

There are several different mechanism of action of zinc on acute diarrhoea. Zinc influences the activity of over 300 enzymes, some of which are responsible for DNA replication and transcription. Zinc promotes immunity, skin and mucosal resistance to infection, growth, and development of the nervous system. It is also an important antioxidant and preserves cellular membrane integrity. At the level of gastrointestinal system, zinc restores mucosal barrier integrity and enterocyte brush-border enzyme activity, it promotes the production of antibodies and circulating lymphocytes against intestinal pathogens.

Most studies about zinc supplementation are acute diarrhea in children. In the present case control study, we examined the effects of zinc supplementation PD children. Here, we investigated the effects of zinc supplementation on serum zinc levels, cell mediated immune status and humoral immune status in young children with PD. Children under zinc group received zinc supplementation in addition to antibiotics and ORS, whereas those under control group received only antibiotics and ORS. This is also a vulnerable time as the babies own antibodies and immunity have yet to develop and the maternal antibodies start to decrease in a child's body [8].

Zinc concentration can be assessed in plasma, hair and urine in detecting zinc deficient states but measuring the serum zinc level has been recommended as an appropriate biomarker [9]. Currently, serum zinc concentration is the most widely used biomarker to determine zinc status. Serum zinc concentrations normally respond to zinc supplementation and thus, it can be considered a useful biomarker of a population's response to zinc interventions [10]. So, in the 
present study, we compared the effect of zinc supplementation among the study groups by measuring serum zinc levels. Since, comparing baseline (before) and post-intervention serum zinc concentrations are a useful way of confirming whether the intervention is reaching the intended beneficiaries, we measured the serum zinc levels once at enrollment and again after 120 days of treatment.

At the time of enrollment, the serum zinc concentration was $4.37 \pm 1.23$ $\mu \mathrm{mol} / \mathrm{L}$ in zinc group and $4.42 \pm 1.45 \mu \mathrm{mol} / \mathrm{L}$ in control group with a P-value of $>0.05$ showing no statistically significant difference between zinc and control group in serum zinc concentrations. However, after treatment the serum zinc concentrations in the zinc group was significantly higher $(8.81 \pm 2.56 \mu \mathrm{mol} / \mathrm{L})$, as compared to the control group $(4.12 \pm 1.02 \mu \mathrm{mol} / \mathrm{L})$. Therefore, children who were not given zinc supplements generally had stable or declining serum zinc concentrations probably reflecting net loss of zinc during diarrhea which is supported by the Castillo-Duran C et al. [11]. and Ruz M, et al. [12] in their studies. Whereas, those children who were zinc-supplemented had increment in serum zinc concentrations, indicating the effect of the supplement. Thus, the present study justified the statistically significant positive effect of zinc supplementation in serum zinc levels in PD. It clearly showed the improvement in serum zinc levels in PD after providing zinc supplementation in addition to ORS and antibiotics rather than providing antibiotics and ORS alone. The result is similar to the study done by Sachdev HP, et al. [13] which also showed improvement in serum zinc status following oral zinc administration in children with PD. Similarly, Baqui AH, et al. [14] reported that zinc supplementation enhanced serum zinc concentration when given as a treatment for diarrhea and helped children maintain a more adequate zinc status during the convalescent period.

In the present study, oral zinc supplementation for 120 days improved the parameters of both cell-mediated and humoral immunity among zinc groups. Whereas, in control groups, there was deterioration of immune status. The deterioration of immune status in children between baseline and 120 days is consistent with the finding of worsening zinc status between baseline and 120 days in the unsupplemented group. It is clear from many studies that zinc affects multiple aspects of the immune system, from the barrier of the skin to gene regulation within lymphocytes [15]. In-vitro studies and studies on zinc-deficient patients have demonstrated that zinc plays an essential role in both cell-mediated and humoral immunity [16]. Zinc deficiency affects development of acquired immunity by preventing both the outgrowth and certain functions of $\mathrm{T}$ lymphocytes activation, Th1 cytokine production, and B lymphocyte help functions [15]. Likewise, B lymphocyte development and antibody production, particularly immunoglobulin G, is compromised [17]. Thus, zinc deficiency is associated with many immunologic deficits, and zinc supplementation was shown to improve immune function in children in developing countries [15] [17] and to reduce the incidence and prevalence of diarrhea. 
In the present study, zinc supplementation improved the important classic parameters of cell-mediated immune competence the number of circulating T-lymphocytes, especially CD4+ cells percentage and the ratio of CD4+/CD8+ with no statistically significant difference in CD3+\% and CD8+\%. These findings are consistent with the study done by Sunil $\mathrm{S}$ et al. [17] which also showed significantly higher rise in the geometric means of CD4 $(64 \% P=0.001)$, and $\mathrm{CD} 4 / \mathrm{CD} 8$ ratio $(73 \% P=0.004)$ with no difference in CD8 among zinc groups, but regarding $\mathrm{CD} 3$, the study reported significantly higher rise in the geometric means of CD3 $(25 \%, P=0.02)$ among zinc groups which is inconsistent with our study.

Regarding humoral immunity, the present study showed improvement in IgG, and IgM levels with no statistically significant difference in IgA levels following 120 days of oral zinc supplementation among zinc groups. Our findings are comparable with the study done by Muhammad J, et al. [18] which showed that zinc supplementation given as adjunct therapy during acute shigellosis had beneficial effects both clinically and in modulating the systemic humoral and cellular immune responses for increased host defense. Another study by Rubhana Raqib, et al. [19] showed that 2 weeks of zinc supplementation during acute shigellosis enhanced antigen-specific antibody (Ipa-specific immunoglobulin G response) as well as lymphocyte proliferation responses in the peripheral circulation.

Results of the study suggest that zinc supplementation may provide significant nutritional, immunological and clinical benefits to children during the episodes of PD. Moreover, zinc used as a treatment for diarrhea reduces mortality in children.

The role of zinc in diarrhea may be mediated through several mechanisms. The possible mechanisms for the effect of zinc supplementation on diarrhea include improved intestinal absorption of water and electrolytes, quicker regeneration of the gut epithelium, increased levels of enterocyte brush border enzymes, and improved immune responses. This is thought to lead to rapid clearance of diarrheal pathogens from the intestine [20]. There are some limitations in this study, for example, the sample size is small and the treatment is not the same, some used antibiotics and some not, because of retrospective design. The further study of the zinc how to affect immune status of the children with PD is needed.

\section{Conclusion}

The administration of zinc supplement in the PD children of age from 6 to 24 months for 120 days has a beneficial effect. In the present study, children who received zinc supplements showed a marked improvement in serum zinc levels and immunological parameters particularly CD4+\%, CD4+/CD8+ ratio and IgG and IgM levels, suggesting that zinc supplementation has a significant positive effect on serum zinc levels and immune status. So, here we conclude that oral zinc supplementation is a simple and effective therapeutic intervention in the 
management of persistent diarrhea. Thus, we recommend the use of zinc supplement as adjunctive therapy in all the episodes of diarrhea to improve the management of diarrhea [21].

\section{Conflicts of Interest}

The authors declare no conflicts of interest regarding the publication of this paper.

\section{References}

[1] Lv, Z., Wang, Y., Yang, T., et al. (2016) Vitamin A Deficiency Impacts the Structural Segregation of Gut Microbiota in Children with Persistent Diarrhea. Journal of Clinical Biochemistry and Nutrition, 59, 113-121. https://doi.org/10.3164/jcbn.15-148

[2] Black, R.E., Morris, S.S. and Bryce, J. (2003) Where and Why Are 10 Million Children Dying Every Year. The Lancet, 361, 2226-2234. https://doi.org/10.1016/S0140-6736(03)13779-8

[3] Liu, L., Oza, S., Hogan, D., et al. (2015) Global, Regional, and National Causes of Child Mortality Rates in 2000-13, with Projections to Inform Post-2015 Priorities on Updated Systematic Analysis. The Lancet, 385, 430-440. https://doi.org/10.1016/S0140-6736(14)61698-6

[4] Andrade, J.A. and Fagundes-Neto, U. (2011) Persistent Diarrhea: Still an Important Challenge for the Pediatrician. Jornal de Pediatria, 87, 199-205.

https://doi.org/10.2223/JPED.2087

[5] Chaudhari, V.P., Patel, J., et al. (2017) Pharmacoepidemiological Profile and Appropriateness of Drug Use in Paediatric Diarrhoea Patients: A Cross Sectional Study in Western India. International Journal of Basic \& Clinical Pharmacology, 6, 2062-2069. https://doi.org/10.18203/2319-2003.ijbcp20173297

[6] Kelkitli, E., Ozturk, N., Aslan, N.A., et al. (2016) Serum Zinc Levels in Patients with Iron Deficiency Anemia and Its Association with Symptoms of Iron Deficiency Anemia. Annals of Hematology, 95, 751-756. https://doi.org/10.1007/s00277-016-2628-8

[7] Kleine, T.O. and Merten, B. (1980) Rapid Manual Immunoturbidimetric and Immunonephelometric Assays of Prealbumin, Albumin, IgG, IgA and IgM in Cerebrospinal Fluid. Journal of Clinical Chemistry and Clinical Biochemistry, 18, 245-254. https://doi.org/10.1515/cclm.1980.18.4.245

[8] Panchal, J.R., Desai, C.K., Iyer, G.S., et al. (2013) Prescribing Pattern and Appropriateness of Drug Treatment of Diarrhoea in Hospitalized Children at a Tertiary Care Hospital in India. International Journal of Medicine and Public Health, 3, 335-341. https://doi.org/10.4103/2230-8598.123522

[9] Mandal, K. and Lu, H. (2017) Zinc Deficiency in Children. International Journal of Science Inventions Today, 6, 009-019.

[10] Hess, S.Y., Peerson, J.M., King, J.C. and Brown, K.H. (2007) Use of Serum Zinc Concentration as an Indicator of Population Zinc Status. Food and Nutrition Bulletin, 28, S403-S429. https://doi.org/10.1177/15648265070283S303

[11] Castillo-Duran, C., Vial, P. and Uauy, R. (1988) Trace Mineral Balance during Acute Diarrhea in Infants. The Journal of Pediatrics, 113, 452-457.

https://doi.org/10.1016/S0022-3476(88)80627-9 
[12] Ruz, M. and Solomons, N.W. (1995) Fecal Excretion of Endogenous Zinc during Oral Rehydration Therapy for Acute Diarrhea. Journal of Trace Elements in Experimental Medicine, 7, 89-100.

[13] Sachdev, H.P., Mittal, N.K. and Yadav, H.S. (1990) Oral Zinc Supplementation in Persistent Diarrhoea in Infants. Annals of Tropical Pediatrics, 10, 63-69. https://doi.org/10.1080/02724936.1990.11747411

[14] Baqui, A.H., Black, R.E., Fischer Walker, C.L., et al. (2006) Zinc Supplementation and Serum Zinc during Diarrhea. Indian Journal of Pediatrics, 73, 493-497. https://doi.org/10.1007/BF02759893

[15] Shankar, A.H. and Prasad, A.S. (1998) Zinc and Immune Function: The Biological Basis of Altered Resistance to Infection. The American Journal of Clinical Nutrition, 68, 447S-463S. https://doi.org/10.1093/ajcn/68.2.447S

[16] Scrimgeour, A.G. and Lukaski, H.C. (2008) Zinc and Diarrheal Disease: Current Status and Future Perspectives. Current Opinion in Clinical Nutrition \& Metabolic Care, 11, 711-717. https://doi.org/10.1097/MCO.0b013e3283109092

[17] Sazawal, S., Jalla, S., Mazumder, S., et al. (1997) Effect of Zinc Supplementation on Cell-Mediated Immunity and Lymphocyte Subsets in Pre-School Children. Indian Pediatrics, 34, 589-597.

[18] Rahman, M.J., Sarker, P., Roy, S.K., et al. (2005) Effects of Zinc Supplementation as Adjunct Therapy on the Systemic Responses in Shigellosis. The American Journal of Clinical Nutrition, 81, 495-502. https://doi.org/10.1093/ajcn.81.2.495

[19] Raqib, R., Roy, S.K., Rahman, M.J., et al. (2004) Effect of Zinc Supplementation on Immune and Inflammatory Responses in Pediatric Patients with Shigellosis. American Journal of Clinical Nutrition, 79, 444-450. https://doi.org/10.1093/ajcn/79.3.444

[20] Ahmed, S., Nasrin, D., Ferdous, F., et al. (2013) Acceptability and Compliance to a 10-Day Regimen of Zinc Treatment in Diarrhea in Rural Bangladesh. Food and Nutrition Sciences, 4, 357-364. https://doi.org/10.4236/fns.2013.44046

[21] Mahfuz, M., Alam, M.A., Islam, S.B., et al. (2017) Treatment Outcome of Children with Persistent Diarrhoea Admitted to an Urban Hospital, Dhaka during 2012-2013. BMC Pediatrics, 17, 142. https://doi.org/10.1186/s12887-017-0896-7 